REPORT

\title{
Autonomous Learning of Elementary Students at Home during the COVID-19 Epidemic: A Case Study of the Second Elementary School in Daxie, Ningbo, Zhejiang Province, China
}

\author{
Zhuodan Xie, ${ }^{1}$ Jiani Yang ${ }^{2}$
}

1. The Second Elementary School of Daxie, Ningbo 315812, Zhejiang, China 2. Jiangsu Second Normal University, Nanjing 210013, Jiangsu, China

\begin{abstract}
Autonomous learning is a topic of common concern in the education community. Various effective attempts and researches have been made around autonomous learning. However, autonomous learning is carried out more in the context of normal teaching, and lacks the exploration of elementary student autonomous learning outside the normal teaching scene. During the COVID-19 epidemic, the Second Elementary School in Daxie, Ningbo City, Zhejiang Province adopted an online education model to carry out distance education activities and student academic counseling, and actively developed teaching practices for students' independent learning at home. We discuss the teaching practice of home study for students during the school epidemic.
\end{abstract}

Best Evid Chin Edu 2020; 4(2):535-541.

Doi: 10.15354/bece.20.rp009.

Keywords: COVID-19 Epidemic; The Whole Family; Autonomous Learning;

Online Education; Elementary School

\footnotetext{
About the Author: Zhuodan Xie, The Second Elementary School of Daxie, Ningbo 315812, Zhejiang, China. Email: 55479177@qq.com.
}

Correspondence to: Jiani Yang, Jiangsu Second Normal University, Nanjing 210013, Jiangsu, China. Email: 575751641@qq.com.

Conflict of Interests: None. 
A UTONOMOUS learning refers to the ability of learners to set learning goals, determine learning content and progress, choose learning techniques, monitor self-learning processes, and conduct self-assessments (Holec, 1981). It helps students adjust their learning methods and coping strategies in a timely and proactive manner based on learning effects. Studies have shown that students' autonomous learning can effectively improve student learning performance (Zhou \& $\mathrm{Li}, 2020$ ), improve the effectiveness of student learning, and promote the cultivation of lifelong learning abilities Cheng (Guo, 2020).

Affected by the COVID-19 epidemic, schools were unable to carry out teaching activities normally. On February 12, 2020, the Ministry of Education and the Ministry of Industry and Information Technology jointly issued the "Notice on the Work Arrangement of" School's Out, But Class's On "During the Extension of Chinese Elementary School", advocating that "localities combine local learning resources and coordinate arrangements" to use the Internet To achieve "School's Out, But Class's On", i.e., "School is closed, but student learning is continuing online" or "Online Home Study" (This refers to the Official Website of the Chinese Ministry of Education: http://en.moe.gov.cn/), to provide services and support for students' home study (Ministry of Education of the People's Republic of China, 2020).

In order to implement the requirements of the Ministry of Education and the provinces and cities for the "School's Out, But Class's On" during the prevention and control of the COVID-19 epidemic, the Second Elementary School in Daxie, Ningbo City, Zhejiang Province made full use of the online education model to guide students to learn independently. In order to carry out distance education teaching activities and student academic counseling, strive to improve the quality of school students at home, cultivate students' ability to learn at home, minimize the impact of epidemic prevention and control on teaching work in the new semester, and ensure the "School's Out, But Class's On" effectively.

\section{The Basis of Elementary Student Home-Based Self- Learning Practice during the COVID-19 Epidemic}

The school's online education activities require a complete guidance system and welldesigned guidance materials as a guarantee. Without a complete guidance system and well-designed guidance protocol and materials, the school's online teaching activities cannot be carried out. In recent years, the school has actively explored a classroom guidance system based on Protocol-guided Learning and has achieved a series of results, which has provided basic guarantees for the homeschooling practice of elementary students during the COVID-19 epidemic.

\section{Schools Independently Develop Learning Protocol for Students' Independent Learning}


Protocol-guided learning is based on curriculum standards and teaching materials for middle and elementary school teachers, combining students' academic situation and cognitive status, taking learning goals as the guidance, and questions as the core, and guiding students' learning before, during, and after class (Xia, 2020).

Since 2010, the school has independently developed task lists and Protocolguided Learning suitable for students' learning. After years of accumulation, it has a relatively complete set of task lists and Protocol-guided Learning templates, and formed a more comprehensive Protocol-guided learning task, writing and guidance process.

During the epidemic, for the students to study at home independently, the school gave full play to the autonomy and school-based nature of the protocol-guided task list, and organized teachers to study the textbooks, syllabuses, and browse through various materials on the basis of students' actual learning. Break down the key and difficult knowledge, ask different types of questions, and equip them with a certain number of targeted practice questions to form a guided protocol and send them to students, allowing students to form autonomous learning through Protocol-guided Learning habit.

\section{Exploring the Teaching Model of Students'Autonomous Learning}

The "student-centered" teaching model is based on teaching materials as a carrier, closely connecting practical problems with student learning, and focusing on cultivating students' ability to collect information, analyze and solve problems, and then cultivate students' innovative and practical abilities (Lv \& Lv, 2019).

Through years of practice and research, our school has established a relatively complete classroom guidance system. This system changes students' "passive learning" into active learning. Implement two prerequisites: the learning prerequisite and the problem prerequisite. Under the guidance of Protocol-guided Learning, students can reduce the difficulty of learning through self-directed learning, classroom practice, and consolidation after class. With the strategy of "taking students as the mainstay", teachers can organically integrate and carefully design textbooks, and rationally control "learning" and "teaching" in classroom teaching. The purpose is to improve the learning style of students, expand the study time and space of students, and advocate students' independent inquiry. Through self-directed, cooperative, inquiry, exchange, display, feedback and other learning activities, students make students truly masters of learning.

In ordinary classroom learning, by emphasizing learning prerequisites and problem prerequisites, the habit of students' autonomous learning has gradually developed. Therefore, in the face of the epidemic, students in our school can achieve nonclassroom teaching and teacher guidance Use Protocol-guided learning to complete autonomous learning.

\section{Problems Encountered by Students in Autonomous Learning during the COVID-19 Epidemic}


Due to the impact of the epidemic, schools could not carry out teaching activities normally. In order not to affect the normal teaching progress, the school actively responds to national policies, advocates students to learn at home independently, and uses the Internet to achieve "School's Out, But Class's On". However, in the specific implementation process, students often fail to learn autonomously due to various factors. The main issues are as follows:

\section{Due to The Different Family Conditions of Students, It Is Im- possible to Achieve Online Learning That All Students Can Participate In}

Through a questionnaire survey across the school, it was found that $18.7 \%$ of the students in this school do not have mobile phones, iPads, computers and other electronic products; the mobile phone signal is too poor to account for $38.79 \%$; the signal data is not enough to account for $22.41 \%$; there are conflicts in time, only at night Studying accounted for $31.03 \%$; those who would not operate mobile computers accounted for $37.07 \%$; and no city or district digital TV accounted for $39.66 \%$. These factors have prevented the school from fully implementing live webcasting.

\section{Lack of Targeted Autonomous Learning Materials}

In normal classroom teaching, teachers carefully design the teaching process according to the learning objectives of each lesson. By pinpointing the inherent connection between new and old knowledge, we can break through and break down the most difficult points of teaching. Use the students' existing knowledge and experience to guide students from known to unknown and reveal contradictions. Students' ability to cooperate and explore was developed through group discussions.

In the network teaching, due to the limitation of conditions, teaching interaction cannot be realized, and students' autonomous learning is more important. In the true sense of self-study, students should independently think through new self-study textbooks and reference books, relying on existing knowledge, experience, and methods, and learn to explore new knowledge independently. In this process, targeted selflearning materials are of great significance to promote students' autonomous learning. Most of the existing educational materials on the Internet that can be used by students for independent learning are mechanically copying the textbooks, without scientifically deleting, adjusting, integrating, and supplementing the textbooks appropriately to suit the students' actual situation. Therefore, in the specific implementation of online teaching, due to the lack of targeted self-learning materials, students lack the goals and specific learning steps of self-study. They often simply watch instructional videos and complete uniform assignments, which cannot guarantee the learning effect.

\section{Measures Taken by Students to Study Independently During the COVID-19 Epidemic}


Aiming at the problems of students' autonomous study at home during the epidemic, according to the actual situation of the school and referring to the accumulated experience in the past, the following measures were finally determined.

\section{Strengthen the Construction of Online Learning Platforms to Provide the Basis for Students' Autonomous Learning}

Due to the heterogeneous family conditions of school students, students cannot fully participate in online platform learning. The school builds an elementary student online learning platform according to local conditions. For the poor mobile phone signal, insufficient traffic, conflicts in time, can only learn at night, do not operate mobile computers, no problems with digital TV in Ningbo or Daxie, the school carried out through existing public communication platforms, such as QQ group, WeChat group Online learning activities. The school mobilized subject teachers to record teaching microlecture videos in advance, and forwarded the corresponding videos to each class group the next day. Parents can adjust the time by themselves and let the children watch anytime, anywhere to ensure that more children can learn online. Teachers, students and parents are closely linked through QQ group and WeChat group.

For a small number of students who do not have electronic products such as mobile phones, iPads, computers, the school arranges class teachers to contact students in real time to appease anxiety. It is required to submit a home study plan based on the school's study plan and its own learning conditions, and to strengthen home-school communication during this time to ensure students' physical and mental health.

\section{Prepare Targeted Learning Materials to Promote Students' Au- tonomous Learning}

In response to the lack of students' self-learning materials, the school organizes teachers in various disciplines to write and design a guided learning protocol. And make full use of this protocol in the online learning process, to help students clarify learning goals, grasp learning points, lead students to explore laws, improve practical ability, consolidate what they have learned, let students learn to think about problems, learn to summarize and reflect, and promote autonomous learning. School work is arranged as follows:

1. Each class teacher designs a Protocol-guided Learning list according to the learning objectives of the teaching materials and the academic situation of the students, to make the knowledge organized and systematic. Teachers of all disciplines set up lesson preparation groups, and the instructor uploads the designed Protocol-guided Learning list to the lesson preparation group. Teachers of each lesson preparation member discuss and revise them. After the approval of the lesson preparation group leader, the final Protocol-guided Learning list is determined.

2. Before the lesson, the teacher uploads the Protocol-guided Learning list to the class group, and asks the students to preview according to the Protocol-guided Learning list, and requires that they upload to the class group after completing 
the pre-reading part of the study plan, and the teacher corrects it. The Protocolguided Learning list presents learning goals in the form of questions or tasks, enabling students to clarify their learning goals in the preview process, while stimulating students 'interest in autonomous learning, and promoting the improvement of students' autonomous inquiry capabilities.

3. The teacher designs or adjusts the teaching micro-lectures according to the prereading assignments submitted by the students. After the students pre-learn through the Protocol-guided Learning list, they learn independently according to the high-quality micro-lectures uploaded by the teachers, and complete the classroom training in the process. The teacher explains the exercises in this part in the instructional micro-video.

4. The teacher arranges a small amount of homework according to the academic situation. The students complete the exercises and upload the homework to the class group. The teacher judges the student's learning results and gives appropriate guidance.

Elementary student autonomous learning outside the normal teaching scale is a new topic. Although the school has made corresponding attempts, due to the limitations of the school's running conditions, especially the use of students' information technology, many of the school's practices are still very superficial, and need to be continuously researched in the future to promote the better development of elementary student autonomous learning activities.

\section{References}

China Education Daily (2020) There is no need to generally require teachers to record and broadcast courses-relevant persons in charge of the Ministry of Education answer reporters' questions on 'School's Out, But Class's On" 02-12.

Guo, L. (2020) Discrimination and analysis of autonomous learning, inquiry learning and meaningful acceptance learning. Pop Lit Art, (05): 211-222.

Holec, H. (1981) Autonomy and foreign language learning. Oxford: Pergamon, 3.

Lv, Y., Lv, W. (2019) Exploration of the teaching model of student-centered "Electromag- netic Field and Electromagnetic Wave Theory”. Sci Technol Vision, 19:69-71.

Ministry of Education of the People's Republic of China. (2020) Notice on the "Schools Out, But Class's On" Work Arrangement in the Elementary School Extension Period, 0212.

State Council of the People's Republic of China. (2019) China education modernization 2035, $02-23$

Xia, J.P. (2020) Teaching for student learning: Exploration of teaching strategies based on protocol-guided learning. Sci Insigt Edu Front, 5(1):451-467. 
Xie \& Yang. Autonomous Learning of Elementary Students during the COVID-19 Epidemic.

Zhou, L.J., Li, C.G. (2020) Can student selfdirected learning improve their academic performance? Experimental evidence from the instruction of protocol-guided learning in China's elementary and middle schools. Sci Insigt Edu Front, 5(1):469 -480.

Received: 05 March 2020

Revised: 09 March 2020

Accepted: 13 March 2020 